\title{
Tracheo-oesophageal fistula and oesophageal atresia: results of 30 years' experience
}

\author{
MICHAEL P. HOLDEN and GEOFFREY H. WOOLER \\ Department of Cardiothoracic Surgery, The General Infirmary at Leeds, Leeds 1, Yorkshire
}

One hundred and sixteen cases of oesophageal atresia and tracheo-oesophageal fistula operated upon during the period 1939-67 are reviewed. Current views on, initially, surgical care and ultimate management are discussed.

Treatment of this challenging congenital oesophageal disorder was started in this department by Professor Philip Allison in 1939. Initially the procedures undertaken were oesophagostomy with or without external continuity to the exteriorized lower oesophageal segment by means of tubing. It was not until 1945 that the first primary suture was undertaken; the child survived the operation but died the following day. Our first long-term survivor was operated upon in 1949. This compares with Franklin's case at the Hammersmith Hospital in 1947 and the first survival at the Hospital for Sick Children. Great Ormond Street, in 1948.

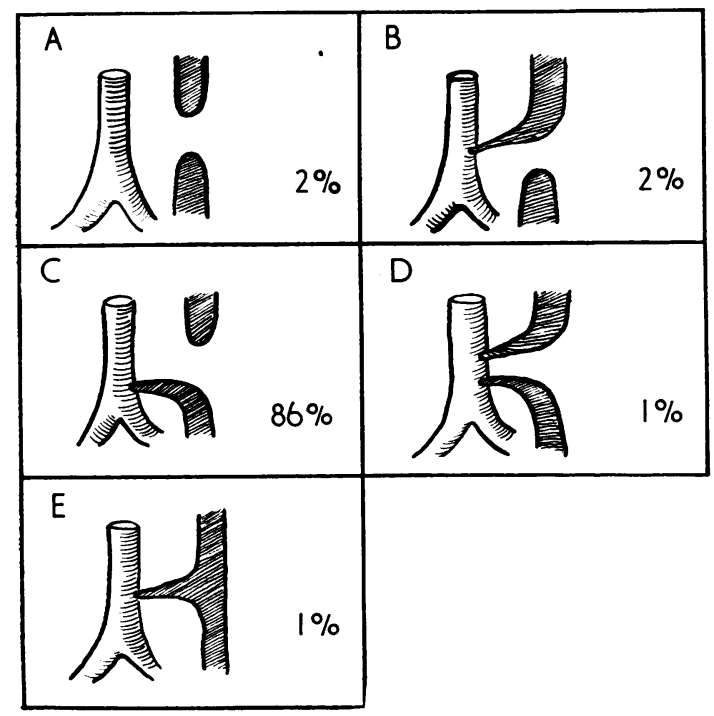

(a)

\section{DEFINITION AND CLASSIFICATION}

Oesophageal atresia with or without tracheooesophageal fistula is an embryological defect occurring during the third to sixth week of intra-uterine life produced by failure of vacuolization and defective apposition of the lateral septa. It is a congenital abnormality which possesses numerous anatomical and surgical variations. In spite of progress in solving the surgical problems, very little progress has been made in classifying the variable deformities. Different classifications have been suggested by Keith (1910), Vogt (1929), Ladd (1944), Swenson (1948), Gross (1953), and

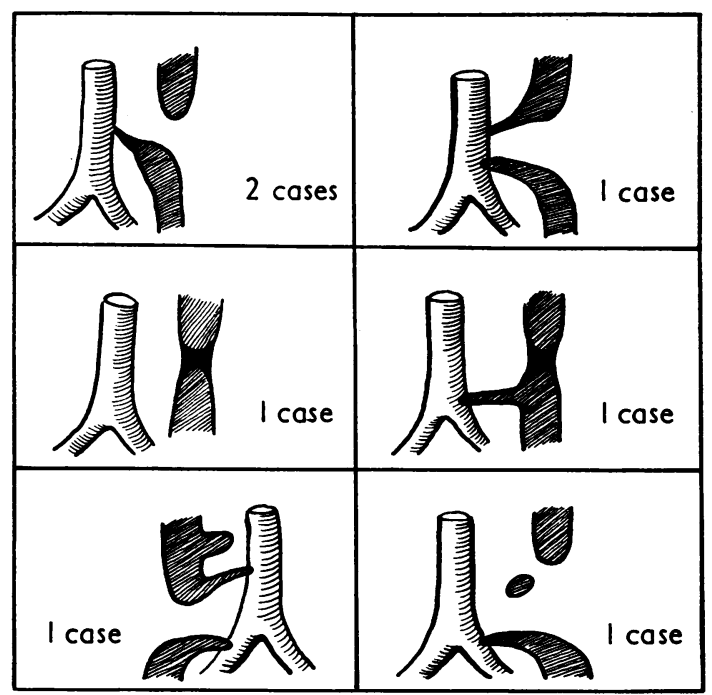

(b)

FIG. 1 (a and b). Anatomical type incidence (Gross (1953) classification). 
Koop, Kiesewetter, and Johnson (1954). Obviously such a variety fosters confusion. We prefer to employ a diagrammatic classification similar to that used by Gross, and, according to Santulli and Amoury (1967), it is the currently accepted classification.

The anatomical variants shown in Fig. $1 \mathrm{a}$ and $b$, which have been encountered in Leeds, demonstrate that, in view of our knowledge of the basic embryological disorganization, an almost infinite number of types could be encountered. This fact is borne out by the large number of case reports by authors which have revealed varying types of fistulae. The precipitating cause of the embryological defect is still uncertain. Speculators have incriminated radiation, maternal disease and drugs affecting DNA synthesis.

The type incidence in various series is presented in Table $I$ incorporating three of the major classifications.
CLINICAL MATERIAL AND SURGICAL MANAGEMENT

In order that all the survivors in this series could be fully reviewed, only cases which were operated upon up to and including 1967 are being considered. During the period 1939 to 1967,116 cases underwent corrective surgery (a further 4 cases died before operation, all of them being over 3 days old). Since January 1968 a further 11 cases have been admitted.

Recently all the patients were interviewed either alone or with their mothers. Heights and weights were measured and were all found to be within the normal range once the child was over 6 years of age. Detailed barium studies from the pharynx to the second part of the duodenum were performed. If there were any symptoms or if there was radiological abnormality, the child was admitted for bronchoscopy and oesophagoscopy, and for clinical confirmation of any of the

T A B L E I

ANATOMICAL TYPE INCIDENCE COMPARISONS

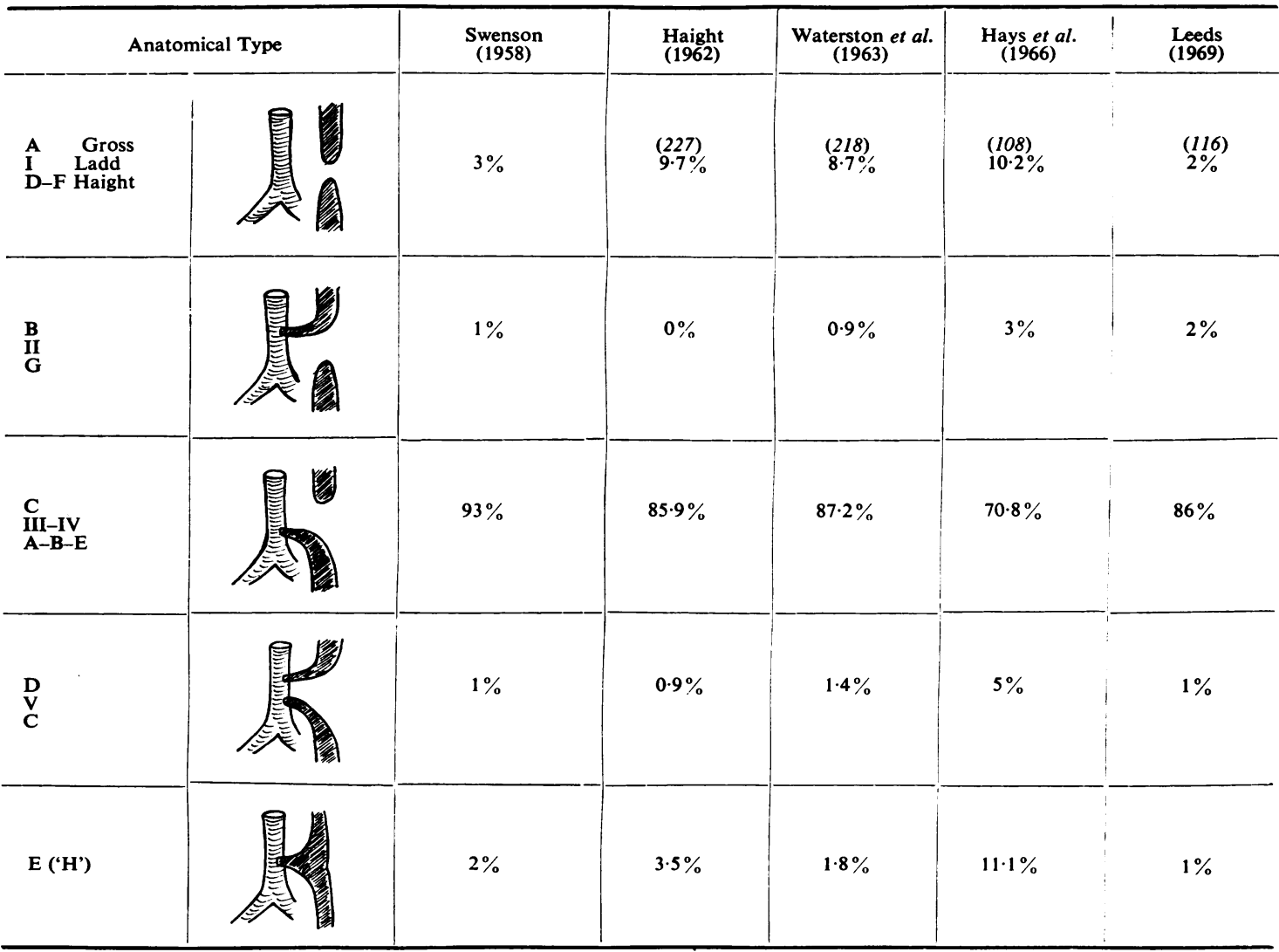


mother's observations. All the children were of average intelligence, except one who had cerebral palsy. The yearly incidence is shown in Figure 2. Increased awareness of the condition by domiciliary midwives and improvement in diagnostic facilities is a reasonable explanation.

Lipiodol or water soluble Gastrografin, never barium, is used to establish a pre-operative diagnosis. Passage of a nasogastric tube does not necessarily confirm the diagnosis. On one occasion one of us (G.H.W.) was able repeatedly to pass a catheter via both oesophageal segments and the intervening trachea when confronted with a case of type D (Gross, Table I).

Following adequate preparation, which will be discussed later, endotracheal anaesthesia is always employed and a right-sided extrapleural approach is used. A two-layer anastomosis is con- structed around a naso-gastric tube (polythene) $\overrightarrow{\vec{F}}$ similar to the method put forward and adoptedo by Haight and Towsley (1943).

MORTALITY Our mortality figures (Fig. 3) are $\mathbb{\Phi}$ comparable with those reported from most large centres : Holder, Cloud, Lewis, and Pilling (1964) कs reported a $40 \%$ mortality. In view of the relatively. small number of cases involved each year, a $\overrightarrow{\vec{\omega}}$ more realistic picture of the mortality trend is $\omega$ seen from Table II. It is generally agreed that the $₹$ main causes of death are: (a) prematurity (with regard to weight (below $5 \frac{1}{2} \mathrm{lb}$.; $2.5 \mathrm{~kg}$.) and 0 gestation); (b) associated congenital abnormalities ; and (c) chest infections.

From Figure 4 it can be seen that there is a 0 marked increase in mortality with regard to prematurity as represented by birth weight.

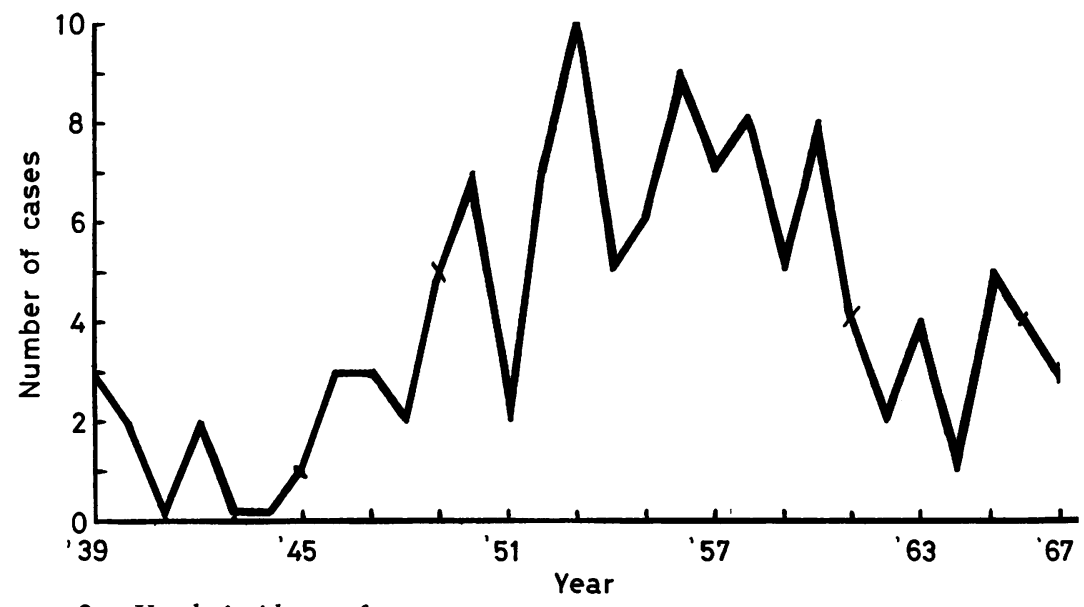

FIG. 2. Yearly incidence of cases.

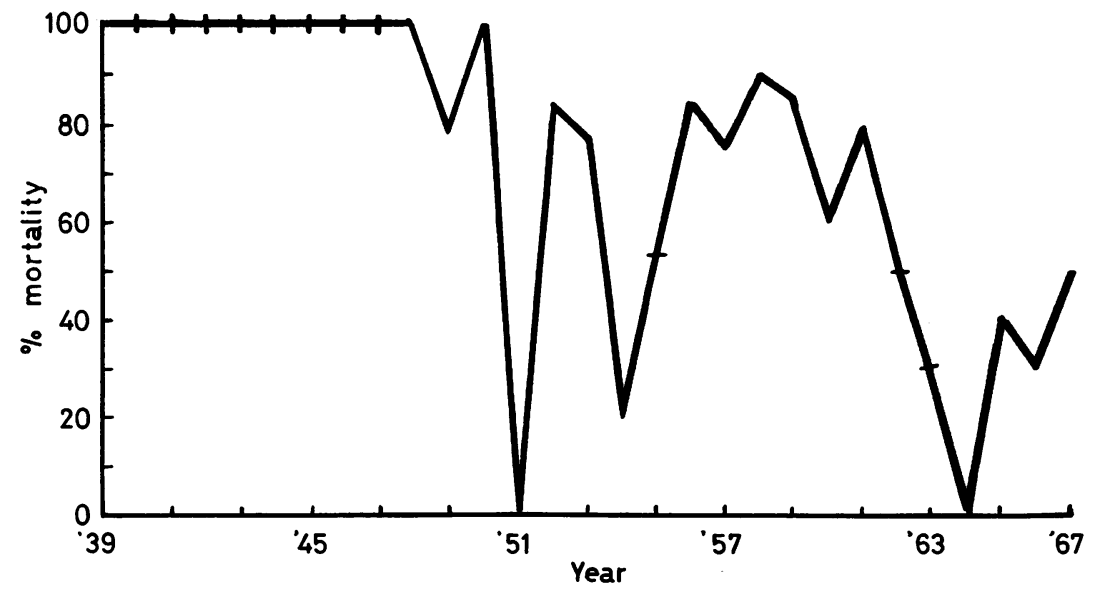

FIG. 3. Annual percentage mortality. 
T A B L E I I

PERCENTAGE FIVE-YEAR MORTALITY

\begin{tabular}{l|c|c|c|c|c|c}
\hline & \multicolumn{7}{|c}{ Year } \\
& \begin{tabular}{c|c|c|c|c}
1939 \\
-42
\end{tabular} & $\begin{array}{c}1943 \\
-47\end{array}$ & $\begin{array}{r}1948 \\
-52\end{array}$ & $\begin{array}{c}1953 \\
-57\end{array}$ & $\begin{array}{c}1958 \\
-62\end{array}$ & $\begin{array}{c}1963 \\
-67\end{array}$ \\
\hline $\begin{array}{l}\text { Total no. } \\
\text { of cases }\end{array}$ & 7 & 4 & 23 & 38 & 29 & 19 \\
\begin{tabular}{l} 
Deaths \\
\hline$\%$
\end{tabular} & 7 & 4 & 19 & 24 & 20 & 7 \\
\hline Mortality & 100 & 100 & 85 & 65 & 73 & 31 \\
\hline
\end{tabular}

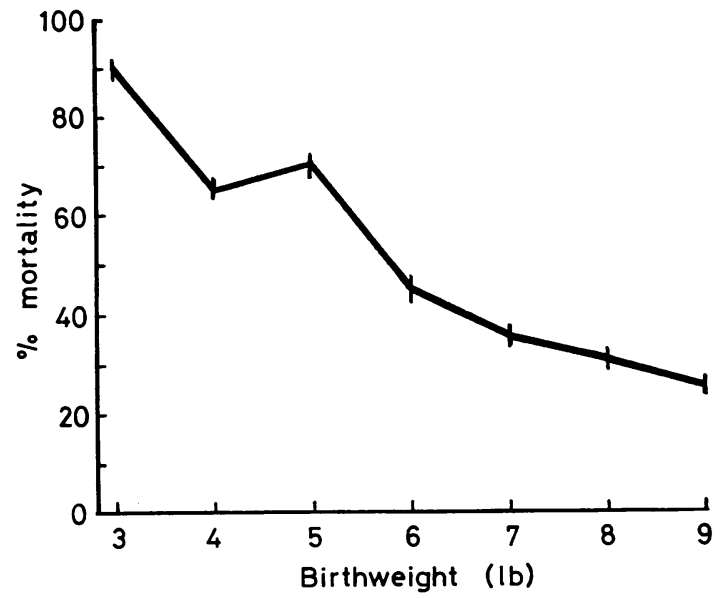

FIG. 4. Association between birth weight (prematurity) and mortality.

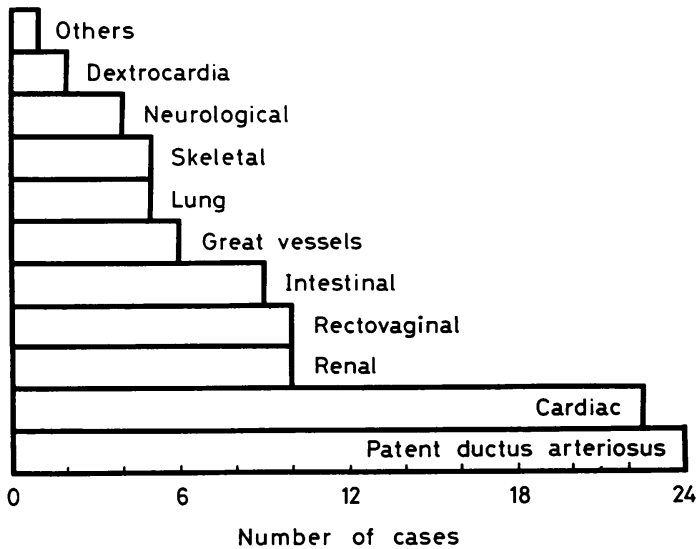

FIG. 5. Incidence of other congenital anomalies: 65 cases had other anomalies-6 are still alive; 28 of the cases had multiple anomalies.

In this series 65 out of 120 patients had other congenital anomalies and of these only 6 are still alive. Twenty-eight of the 65 cases had multiple anomalies. Figure 5 demonstrates the incidence of additional congenital abnormalities. One should always remain aware of the possibility of other defects being present. Pyloric stenosis or duodenal atresia in the lipiodol swallow and when performing the gastrostomy must be excluded. A rectal examination for imperforate anus is never omitted.

The term chest infection covers inhalation pneumonitis to empyema and total atelectasis of a lung. Table III reveals the dramatic fall in the

T A B L E I I I

DECREASING INCIDENCE OF CHEST INFECTIONS POSTOPERATIVELY

\begin{tabular}{c|c|c|c|c|c|c}
\hline & -1939 & 1945 & 1950 & 1955 & 1960 & 1965 \\
& \begin{tabular}{c|c}
1939 \\
-41
\end{tabular} & -49 & -54 & -59 & -64 & -67 \\
\hline $\begin{array}{c}\text { No. with } \\
\text { chest } \\
\text { infection }\end{array}$ & 3 & 10 & 22 & 20 & 9 & 2 \\
\hline $\begin{array}{c}\text { \% of } \\
\text { total }\end{array}$ & 43 & 91 & 64 & 66 & 45 & 14 \\
\hline
\end{tabular}

incidence of chest infection over the last decade ; the probable reasons for this are discussed below. Forty-seven per cent of the deaths in this series have been attributable to chest infections following surgery, and in view of the early death of most of the patients (Fig. 6) it would seem that most of them had an infected chest before surgery was undertaken. Eighty per cent of the deaths during the first 48 hours post-operatively occurred in premature infants. A potent factor in the production of mortality following chest infection is seen in Figure 7. Sex difference seems to be minimal and is recorded in Table IV. Statistically there is no significant difference in our figures.

Twenty-one out of $33(64 \%)$ of the patients who survived the operation (that is, were discharged from hospital) had oesophageal symptoms during the first two years of life, 15 had dysphagia, 13 had anastomotic strictures, and 5 had radiological evidence of hiatus hernia. However, at review only 11 out of $32(35 \%)$ now have any symptoms at all and 2 of them have only dysphagia when suffering from the common cold. One patient developed a peptic stricture associated with a hiatus hernia and will require surgery. Initially he had an anastomotic stricture producing severe dysphagia, but with repeated dilatations and eventually an oesophagoplasty at 6 weeks of age this site of obstruction was relieved, only to be followed later by obstruction further down the oesophagus caused by a peptic stricture (compare other results of oesophagoplasty in Table V). 


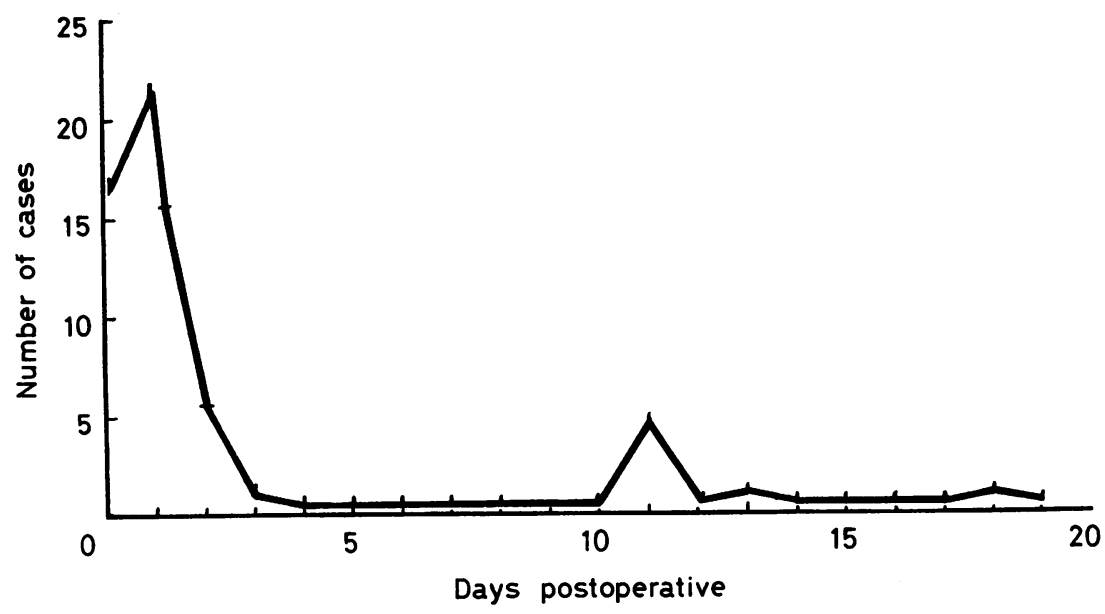

FIG. 6. Post-operative mortality.

TENSION always LEAKAGE $\stackrel{81 \% \text { cases DEATH }}{\longrightarrow}$

FIG. 7. Importance of tension at suture line.

T A B L E IV

ASSOCIATION BETWEEN SEX DIFFERENCES, CONGENITAL ANOMALIES, SURVIVAL AND DEVELOPMENT OF OESOPHAGEAL COMPLICATIONS

\begin{tabular}{c|c|c|c|c}
\hline Sex & $\begin{array}{c}\text { No. of } \\
\text { Cases }\end{array}$ & Anomalies & No. Alive & $\begin{array}{c}\text { Oesophageal } \\
\text { Complica- } \\
\text { tions }\end{array}$ \\
\hline F & 52 & 26 & 15 & 6 \\
M & 64 & 39 & 18 & 13 \\
\hline Total & 116 & 65 & 33 & 21 \\
\hline
\end{tabular}

T A B L E V

PATIENTS REQUIRING TREATMENT FOR STRICTURES

\begin{tabular}{|c|c|}
\hline Procedure and Duration of Treatment & $\begin{array}{l}\text { No. of } \\
\text { Cases }\end{array}$ \\
\hline $\begin{array}{l}\text { Nil } \\
\text { Oesophagoplasty plus dilatations: } \\
\text { at } 6 \text { wk asymptomatic } \\
\text { at } 1 \text { yr-stil has dysphagia } \\
\text { at } 2 \text { yr-peptic stricture } \\
\text { 1 Dilatation: } \\
\text { within } 1 \text { mth of operation } \\
\text { Repeated dilatations: } \\
\text { within } 1-6 \text { mth } \\
\text { within } 6 \text { mth-2 yr } \\
\text { within } 2-5 \text { yr } \\
5 \text { yr post-op. }\end{array}$ & $\begin{array}{l}2 \\
5 \\
5 \\
3 \\
2\end{array}$ \\
\hline
\end{tabular}

As seen above, chest infections cause considerable trouble in the post-operative period, but to our surprise at long-term follow-up only four patients had any respiratory symptoms. One had developed bronchiectasis, and the other three had recurrent winter bronchitis.
DISCUSSION

PLANNING OPERATIVE REgIME Once the initial diagnosis has been established and the approximate classification made, the child should be operated on as soon as possible, assuming that the three main criteria for safety are satisfied: (1) it is not premature; (2) the chest is not infected; and (3) electrolyte imbalance and dehydration have been corrected. Should any of these factors be unsatisfactory and accompanied by another congenital deformity, then a conserva tive staged procedure is undertaken.

Our results confirm what every previous author (see Waterston, Bonham Carter, and Aberdeen, 1962) on this subject has found, namely, that embarking on primary anastomosis immediately in the presence of one or more of the criteria, significantly increases the operative mortality. A staged procedure can be adopted similar to the one suggested and used with success by Holder, McDonald, and Woolley (1962), who reported increased success since not embarking on primary anastomosis in every case initially. Haight (1964) obtained 21 survivors from his last 22 cases. As soon as the premature infant has had respiratory toilet started and has been rehydrated, a gastrostomy is performed under local anaesthesia. Eighteen to 36 hours later the fistula is divided through a retropleural approach, again under local anaesthesia.

It is a debatable point whether these two procedures should be performed simultaneously. Hamilton (1966), when closing the fistula, suggests leaving a long thread for subsequent identification purposes attached to the closed 
distal end of the oesophagus, and at the same time applies a silver clip which provides a clear radiological landmark for estimating the distances between the two oesophageal pouches before attempting a definitive repair. He attempts the primary anastomosis when the child has achieved a weight of 5-6 lb. (2.3-2.7 kg.). Other authors (Hays, Woolley, and Snyder, 1966; Howard and Myers, 1965) advocate mercury bouginage to lengthen the proximal pouch during this interim period. (Steele (1888) was presumably the first to attempt this method.) Lister (1969) claims that bouginage, in cases when a delayed-anastomosis technique is used, can produce infection and ultimately make dissection much more difficult. Cooley, commenting on the paper of Holder et al. (1962), agrees that standardization by weight is a most important step forward, and that the initial gastrostomy and ligation of fistula should be performed as one procedure under local anaesthesia. However, Romsdahl, Hunter, and Grove (1966), reporting a $44 \%$ mortality with 34 cases, feel that primary anastomosis can be completed without delay in almost all cases in spite of the fact that all their patients who died were lighter in weight than those who survived, that is less than $5 \frac{1}{2} . \mathrm{lb}$. $(2.5 \mathrm{~kg}$.). Nor do they feel that the state of the child pre-operatively influences the post-operative survival. All would agree with them that, if the infant is fit according to the above criteria, the mortality increases with increasing delay in surgery from the time of birth.

POST-OPERATIVE DYSPHAGIA Following the operation of definitive anastomosis 20 patients $(61 \%)$ who survived the operation and lived for more than five years (see Table $V$ ) required some further procedure for dysphagia. This represents a high degree of stricture formation which is initially at the anastomotic site. Haight, commenting on the paper by Schultz and Clatworthy (1963), states that now he tries to overcome this problem by routine dilatation of all cases postoperatively. Rather than initially resecting the stricture, oesophagoplasty would appear to offer a reasonable chance of success both in the infant and in the young adult (Keshishian and Cox, 1967). Even when the problem of dysphagia has been solved at the anastomotic site, it is possible for the patient to develop a peptic stricture in the lower third.

OESOPHAGEAL FUNCTION In addition to stenosis another factor may be responsible for causing dysphagia in some cases. This factor is lack of motility. Lind, Blanchard, and Guyda (1966) compared 10 normal children with 10 children who had had the commonest type of fistula repaired, and found that the latter group displayed motility patterns throughout the entire oesophagus indistinguishable from those seen in achalasia. They are of the view that this is a developmental disorder and not of surgical origin. However, Burgess, Carlson, and Ellis (1968), using sophisticated techniques of cinefluoradiography, manometry and Hollander insulin tests on gastric $p \mathrm{H}$, studied nine patients between the ages of 14 and 19 years and arrived at the opposite conclusion, namely, that the decreased motility is due to trauma to oesophageal branches of the autonomic nervous system due to excessive 'stripping' of the paraoesophageal tissue in an attempt to gain more length when preparing the anastomosis. Eight of Burgess's nine patients had excellent clinical results and all showed aperistaltic segments beginning 1.0 to $4.0 \mathrm{~cm}$. below the pharyngo-oesophageal sphincter and extending 6.0 to $15.0 \mathrm{~cm}$. down the oesophagus to a completely normal cardiac sphincter. We were unable to use these techniques in this follow-up, but all patients underwent barium studies where 50 rapid sequence plates were taken. Three patients were found to have a non-motile lower third of the oesophagus. On questioning, these patients had occasional difficulties with meat, fish, bread, and fruit skins, yet symptoms occurred so infrequently that they never had to seek surgical advice. At oesophagoscopy no abnormality could be found. On reviewing the operative notes of these three cases it was found that extensive mobilization of the oesophageal segments had been necessary in order to approximate the two ends.

PRODUCTION OF HIATUS HERNIA The above manœuvres of 'freeing' the distal segment in order to gain apposition of the two oesophageal pouches is doubtless responsible for producing a second problem-hiatus hernia-by creating a 'short oesophagus'. Five of the surviving 33 patients were found to have a hiatus hernia during the first six months of life. At review, one is symptomfree and radiologically normal, a second has no symptoms yet has a pronounced hernia demonstrable with barium, and the third has a demonstrable hernia which produced oesophagitis and occasional dysphagia with probable immobility. The fourth has developed a peptic stricture which will require surgical correction, and the last one died aged 6 years from bronchiectasis. 


\section{CONCLUSIONS}

The following points are, we consider, important : 1. Confirm the diagnosis early, especially in cases where the mother had polyhydramnios.

2. Pre-operative preparation rather than emergency definitive surgery is preferred.

3. Avoid tension at the anastomotic site in order to prevent breakdown and leakage. Excessive mobilization can produce non-motile segments, hiatus hernia, and subsequent peptic stricture. Alternative procedures of jejunal or colon trans. plants at the age of 18 months are preferable.

4. Extrapleural approach with drainage is advocated in an attempt to avoid infecting the pleural space.

5. Extreme care should be taken in the preoperative and immediate post-operative period with respiratory hygiene and fluid and electrolyte balance.

6. Make a guarded prognosis in premature infants with other anomalies.

7. Use post-operative dilatation in all cases.

We are grateful to have been able to include in this series patients under the care of Professor P. R. Allison and the late Mr. J. A. Aylwin.

We also wish to thank the anaesthetists, whose preoperative and post-operative care has been a great help.

\section{REFERENCES}

Burgess, J. N., Carlson, H. C., and Ellis, F. H (1968). Esophageal function after successful repair of esophageal atresia and tracheoesophageal fistula. J. thorac. cardiovasc Surg., 56, 667.

Franklin, R. H. (1947). Congenital atresia of the oesophagus-two cases successfully treated by anastomosis. Lancet, $2,243$.

Gross, R. E. (1953). The Surgery of Infancy and Childhood, p. 76. Saunders, Philadelphia.

Haight, C. (1962). Congenital oesophageal atresia and tracheooesophageal fistula. Paediat. Surg., 1, 266.
(1964). Congenital atresia of the esophagus. Postgrad. Med., $\overrightarrow{\bar{*}}$ $36,463$.

- and Towsley, H. A. (1943). Congenital atresia of the eso-O phagus with tracheoesophageal fistula. Extrapleural ligation of fistula and end-to-end anastomosis of esophageal segments. Surg. Gynec. Obstet., 76, 672.

Hamilton, J. P. (1966). Oesophageal atresia. Technical points in the $\vec{\nabla}$ staged procedures leading to esophageal anastomosis. J. Pediat. $\mathrm{O}$ Surg., 1, 253.

Hays, D. M., Woolley, M. M., and Snyder, W. H. (1966). Esophageal atresia and tracheoesophageal fistula: Management of the uncommon types. J. Pediat. Surg., 1, 240.

Holder, T. M., Cloud, D. T., Lewis, J. E. and Pilling, G. P. (1964) $\cdot-$ Oesophageal atresia and tracheo-oesophageal fistula. Paediatrics, $\vec{\omega}$ $34,542$.

- McDonald, V. G., Jr., and Woolley, M. M. (1962). The premature or critically ill infant with esophageal atresia: increased success with a staged approach. J. thorac. cardiovasc. increased success with a staged approach. J. Thorac. cardiovasc. in
Surg., 44, 344.

Howard, R., and Myers, N. A. (1965). Esophageal atresia: a technique for elongating the upper pouch. Surgery, 58, 725.

Keith, A. (1910). A demonstration of constrictions and occlusions $\vec{A}$ of the alimentary tract of congenital or obscure origin. Brit. med. J., 1,301

Keshishian, J. M., and Cox, P. A. (1967). Esophageal stricture at anastomotic site following repair of tracheoesophageal fistula: a nineteen-year follow-up. J. thorac. cardiovasc. Surg., 53, 754. C

Koop, C. E., Kiesewetter, W. B., and Johnson, J. (1954). Treatment of atresia of the esophagus by the transpleural approach. Surg. Gynec. Obstet., 98, 687.

Ladd, W. E. (1944). The surgical treatment of esophageal atresia $\vec{\theta}$ and tracheoesophageal fistula. New Engl. J. Med., 230, 625. ㄱ

Lind, J. F., Blanchard, R. J., and Guyda, H. (1966). Esophageal ${ }^{\circ}$ motility in tracheoesophageal fistula and esophageal atresia. Surg. Gynec. Obstet., 123, 557.

Lister, J. (1969). Complications of the repair of oesophageal atresia. In Recent Advances in Paediatric Surgery, ed. Wilkinson, A. W., 2nd ed., p. 121. Churchill, London.

Romsdahl, M. M., Hunter, J. A., and Grove, W. J. (1966). Tracheo-气̊ esophageal fistula and esophageal atresia: surgical management $\mathbb{D}$ and results at a university hospital. $J$. thorac. cardiovasc. 으 Surg., 52, 571.

Santulli, T. V., and Amoury, R. A. (1967). Congenital anomalies of the gastrointestinal tract. Pediat. Clin. N. Amer., 14, 21.

Schultz, L. R., and Clatworthy, H. W. (1963). Esophageal structures after anastomosis in esophageal atresia. Arch. Surg., 87, 120

Steele, C. (1888). Case of deficient oesophagus. Lancet, 2, 764.

Swenson, O. (1948). The diagnosis and treatment of atresia of the esophagus and tracheoesophageal fistula. Pediatrics, 1, 195

- (1958). Paediatric Surgery, Appleton-Century-Crofts, New York.

Vogt, E. C. (1929). Congenital esophageal atresia. Amer. J. Roent genol., 22, 463.

Waterston, D. J. Bonham Carter, R. E., a nd Aberdeen, E. (1962) Oesophageal atresia: Tracheo-oesophageal fistula. A study of survival in 218 infants. Lancet, 1, 819 .

Lancet, 255. 